\title{
ChemComm
}

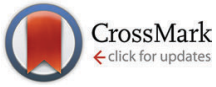

Cite this: Chem. Commun., 2015, 51,14724

Received 16th July 2015, Accepted 10th August 2015

DOI: $10.1039 / \mathrm{c5cc05913e}$

www.rsc.org/chemcomm

\section{A vanadium(Iv) pyrazolate metal-organic polyhedron with permanent porosity and adsorption selectivity $\dagger$}

\author{
A. W. Augustyniak, ${ }^{\star a}$ M. Fandzloch, ${ }^{b}$ M. Domingo, ${ }^{c}$ I. Łakomska ${ }^{b}$ and \\ J. A. R. Navarro*C
}

A vanadium(IV) pyrazolate-based open metal-organic polyhedron of $\left.\mathrm{V}_{3}\left(\mu_{3}-\mathrm{O}\right) \mathrm{O}(\mathrm{OH})_{2}\left(\mu_{4}-\mathrm{BPD}\right)_{1.5}(\mu-\mathrm{HCOO})_{3}\right]$ (BDP = benzene-1,4-bipyrazolate) formulation gives rise to a porous crystal structure exhibiting micro and mesoporosity which is useful for selective adsorption of gases.

Metal-organic polyhedra (MOPs) are discrete molecular architectures constructed via the coordination of metal ions and organic linkers to yield highly structured polyhedra. These systems usually possess a cavity able to incorporate host molecules thereby modifying their reactivity and dynamics. ${ }^{1}$ These features put these systems in close resemblance to biological self-assembled container supramolecules such as ferritin which play fundamental roles in regulating major physiological functions. ${ }^{2}$ MOPs are also interesting since they can be considered as the building units of MOFs, ${ }^{3}$ however, their discrete nature confers them a highly processable nature. ${ }^{4-6}$ On the other hand, vanadium ions are very attractive building units since their coordination diversity and redox activity give rise to a rich variety of predefined SBUs and catalytic activity. ${ }^{7-17}$ Noteworthily, the hard acidic nature of vanadium gives rise to the preferred use of O-donor linkers (i.e. phosphonate and carboxylates) for the construction of MOPs and MOFs. ${ }^{18-24}$ However, the enhanced basicity of some nitrogen-donor pyrazolate ligands has proven to give rise to highly stable constructs with $\mathrm{Ni}_{3}(\mathrm{BTP})_{2}\left(\mathrm{BTP}=1,3,5\right.$-tris $\left(1 H^{-}\right.$ pyrazol-4-yl)benzene) being a remarkable example of high chemical and thermal stability making them potentially useful for application under harsh experimental conditions. ${ }^{25-31}$

In this communication, we show that the reaction of $\mathrm{VCl}_{3}$ and $\mathrm{H}_{2} \mathrm{BDP}$ (1,4-bi(1H-pyrazol-4-yl)benzene), in DMF under solvothermal

\footnotetext{
${ }^{a}$ Institute of Public Health and Environmental Protection, Batystowa 1B, 02-835 Warsaw, Poland. E-mail: adam.augustyniak1@gmail.com

${ }^{b}$ Faculty of Chemistry, Nicolaus Copernicus University, Gagarina 7 , 87-100 Toruń, Poland

'Departamento de Química Inorgánica, Universidad de Granada, Av. Fuentenueva S/N, 18071 Granada, Spain.E-mail: jarn@ugr.es

$\dagger$ Electronic supplementary information (ESI) available: Synthesis of MOP and linker molecules, XPRD patterns, IR, TG and EPR measurements. CCDC 1412183. For ESI and crystallographic data in CIF or other electronic format see DOI: $10.1039 / \mathrm{c} 5 \operatorname{cc} 05913 \mathrm{e}$
}

conditions at $423 \mathrm{~K}$, gives rise to single crystals of a system of $\left[\mathrm{V}_{3}\left(\mu_{3}-\mathrm{O}\right) \mathrm{O}(\mathrm{OH})_{2}\left(\mu_{4}-\mathrm{BPD}\right)_{1.5}(\mu-\mathrm{HCOO})_{3}\right]$ (1) formulation. The formation of formate anions should be regarded as a consequence of the hydrolysis of DMF solvent molecules during the solvothermal reaction. The crystallographic study of 1 reveals that its molecular structure is based on triangular trinuclear vanadium(Iv) SBUs of the $\left[\mathrm{V}_{3}\left(\mu^{3}-\mathrm{O}\right) \mathrm{O}(\mathrm{OH})_{2}(\mu-\mathrm{HCOO})_{3}\right]$ type in which the vanadium centres exhibit a typically distorted octahedral $\mathrm{VN}_{2} \mathrm{O}_{4}$ stereochemistry. ${ }^{14}$ These triangular SBUs are connected by exotetradentate benzene-1,4-bipyrazolate (BDP) to give rise to the formation of tetrahedral MOPs with $1.2 \mathrm{~nm}$ inner cavities accessible through $0.85 \mathrm{~nm}$ wide triangular windows (see Fig. 1). \$ Noteworthily, MOP packing in the crystal structure follows a bcc arrangement which gives rise to $0.85 \mathrm{~nm}$ inter nanocage voids. Calculation of the Connolly surface of the crystal structure gives rise to high values of potentially accessible surface area for a probe molecule of $1.4 \AA$, namely $1660 \mathrm{~m}^{2} \mathrm{~g}^{-1}$ and an accessible pore volume of $0.130 \mathrm{~cm}^{3} \mathrm{~cm}^{-3}$ (Fig. 1C). In view of both the intra and inter cage porosity, we thought that this material might be useful for gas separation and purification purposes (see below). The physico-chemical nature of $\mathbf{1}$ was further studied by means of IR, EPR, TGA and XRPD (see the $\mathrm{ESI} \dagger$ ). Both room temperature EPR spectra of 1, exhibiting a sharp isotropic signal with a $g$ value of 1.996, and IR spectra showing the apparition of the band at $953 \mathrm{~cm}^{-1}$ characteristic of $\mathrm{V}=\mathrm{O}$ agree with the observed octahedral environment of vanadium(IV) centres. X-ray powder diffraction (XPRD) patterns of $\mathbf{1}$ are indicative of the phase purity of the bulk material. Thermogravimetric analysis of $\mathbf{1}$ in an atmosphere of air (Fig. S4, $\mathrm{ESI} \dagger$ ) reveals a significant weight loss $(34 \%)$ of the material in the 373-503 $\mathrm{K}$ temperature range which corresponds to the loss of water and DMF solvent molecules. Above this temperature the desolvated material remains thermally stable up to $568 \mathrm{~K}$. The permanent porosity of $\mathbf{1}$ was verified by the $\mathrm{N}_{2}$ adsorption isotherm at $77 \mathrm{~K}$ (Fig. 2), which reveals a type-I isotherm with a moderate value of BET surface area of $260 \mathrm{~m}^{2} \mathrm{~g}^{-1}$ and an adsorption capacity of $4.6 \mathrm{mmol} \mathrm{g}^{-1}$ at $0.8 P / P_{\mathrm{o}}$. Additionally, the presence of a (type $\mathrm{H} 4$ ) hysteresis is indicative of textural 

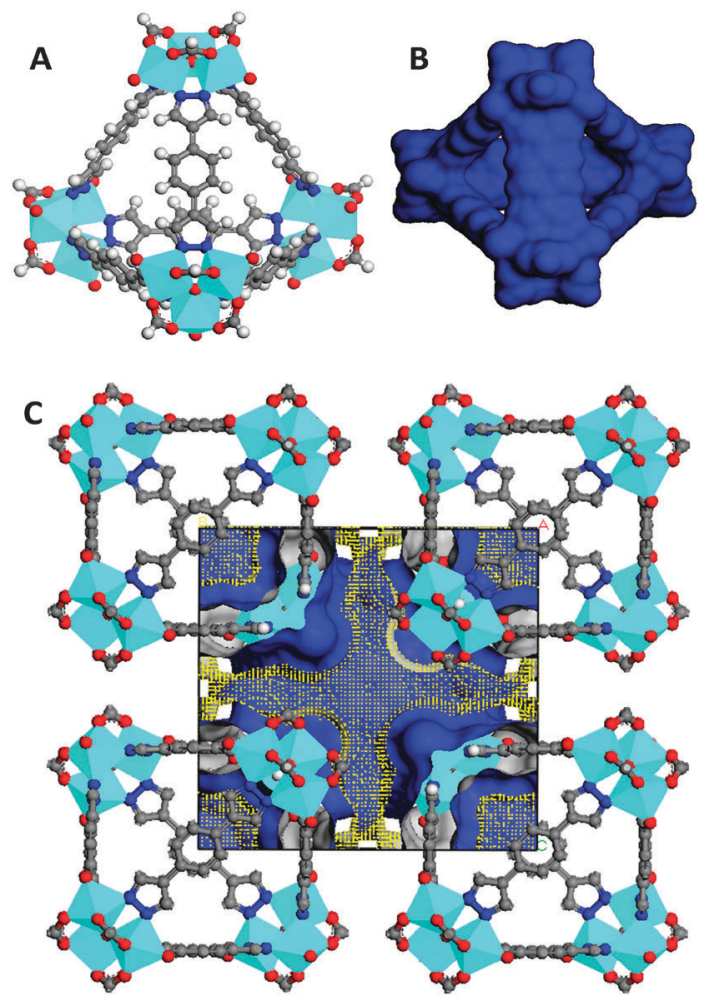

Fig. 1 View of the molecular structure of a tetrahedral metal-organic polyhedron found in the crystal structure of 1 in the form of polyhedra (A), van der Waals surface (B) and Connolly surface of the crystal packing (C).

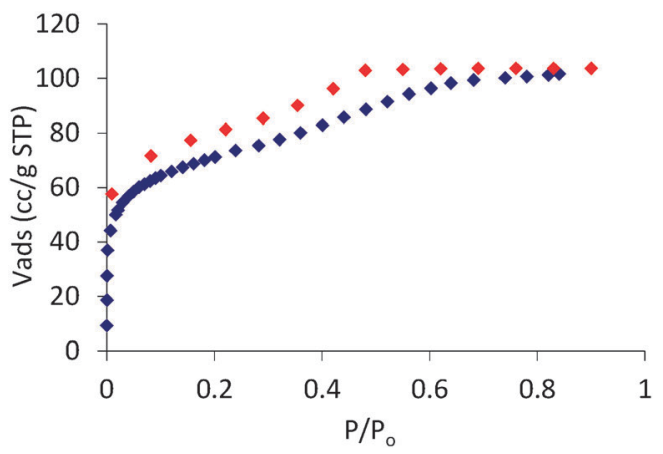

Fig. $2 \mathrm{~N}_{2}$ adsorption (blue symbols) and desorption (red symbols) measured at $77 \mathrm{~K}$.

mesoporosity arising from interparticle mesopores. Indeed, porosity distribution by density functional theory indicates, as implemented in Micromeritics software, the presence of both micropores of $c a$. $1.5 \mathrm{~nm}$ (inside cages) and mesopores of $5 \mathrm{~nm}$ (interparticle).

The appearance of mesoporosity, which is not observed in the crystal structure of $\mathbf{1}$ might be responsible for the observed higher pore volume accessibility than the calculated one from the crystal structure (the experimental accessible volume of $0.150 \mathrm{~cm}^{3} \mathrm{~cm}^{-3}$ vs. the calculated value of $0.130 \mathrm{~cm}^{3} \mathrm{~cm}^{-3}$ ), should be related to a partial loss of supramolecular ordering after sample desolvation. By contrast, the observed BET surface area is considerably lower than the calculated one from the Connolly surface for a probe molecule of $1.4 \AA\left(260 \mathrm{~m}^{2} \mathrm{~g}^{-1}\right.$ vs. $\left.1660 \mathrm{~m}^{2} \mathrm{~g}^{-1}\right)$ which might be indicative of poor accessibility of the probe molecule to the whole crystal porosity after sample activation (see below).

Indeed, XRPD of 1 after thermal activation indicates that although the original XRPD pattern is maintained a certain degree of amorphization is obvious which may give rise to the observed hierarchical pore structure and to the observed slow diffusion of $\mathrm{N}_{2}$ molecules inside the pore structure which is manifested by long equilibration times during the adsorption measurements.

Once we proved the accessible nature of the porous structure of 1 we proceed to evaluate its possible utility in gas and vapor separation processes, namely $\mathrm{CO}_{2}$ capture from flue gas and benzene/cyclohexane separation. Fig. 3 shows the $\mathrm{CO}_{2}$ adsorption isotherms of $\mathbf{1}$ at 273 and $298 \mathrm{~K}$ as well as a comparison of $\mathrm{N}_{2}$ and $\mathrm{CO}_{2}$ adsorption isotherms at $273 \mathrm{~K}$. The $\mathrm{CO}_{2}$ adsorption isotherms of $\mathbf{1}$ follow a type-I behavior in the studied pressure range. The isosteric heats of $\mathrm{CO}_{2}$ adsorption were evaluated according to the Clausius-Clapeyron (eqn (1)) from the adsorption isotherms measured at 273 and $298 \mathrm{~K}$ :

$$
q_{\mathrm{st}}=-R\left(\frac{\mathrm{d} \ln P}{\mathrm{~d}\left(\frac{1}{T}\right)}\right)_{N}
$$

where $q_{\mathrm{st}}, R, P$, and $N$ represent isosteric heat of adsorption, gas constant, pressure, and the amount of adsorption of $\mathrm{CO}_{2}$,
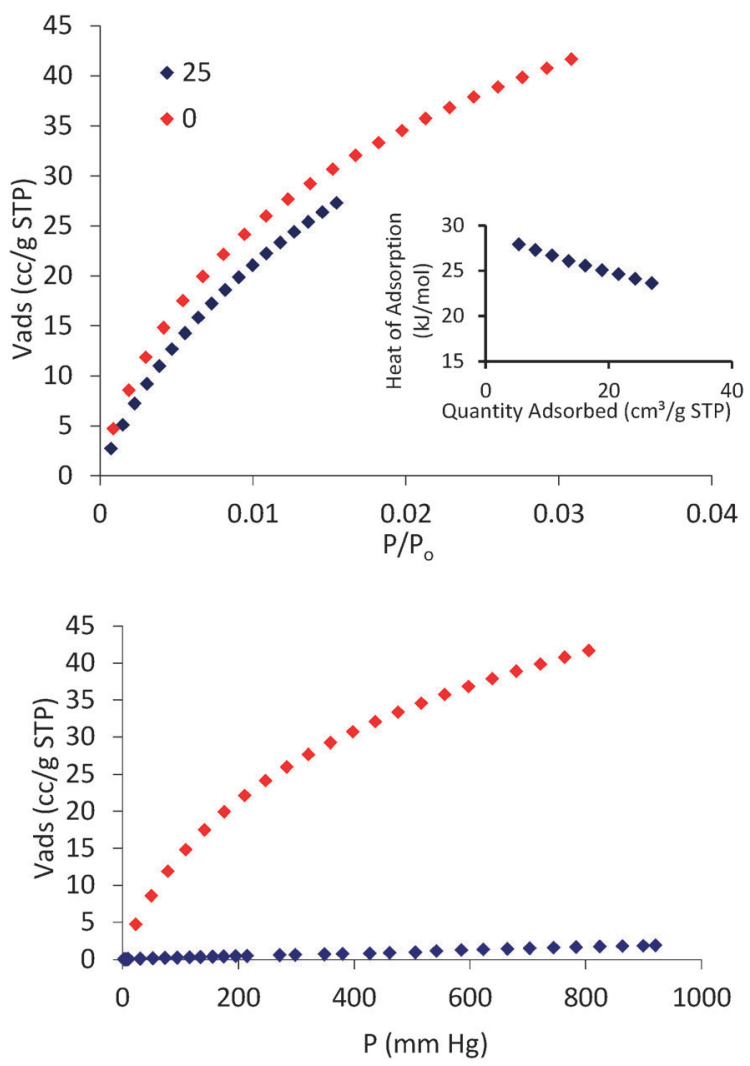

Fig. $3 \mathrm{CO}_{2}$ adsorption isotherms measured at $273 \mathrm{~K}$ (red) and $298 \mathrm{~K}$ (blue) (top), $\mathrm{CO}_{2}$ isosteric heat of adsorption (inset in top) and $\mathrm{CO}_{2} / \mathrm{N}_{2}$ selectivity at $273 \mathrm{~K}$ (down). 


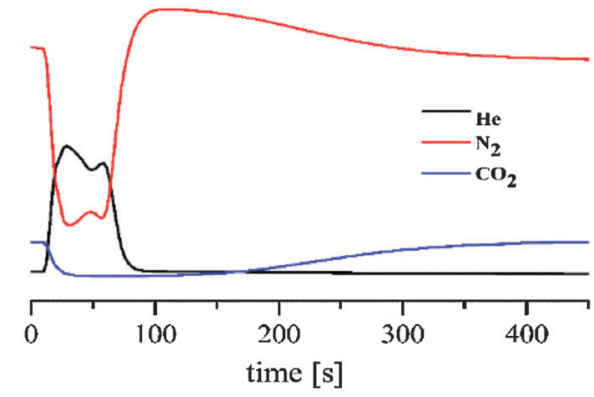

Fig. $4 \quad \mathrm{~N}_{2} / \mathrm{CO}_{2}$ separation breakthrough experiments at $273 \mathrm{~K}$ of a column packed MOP 1

respectively. The results show that $\mathrm{CO}_{2}$ molecules interact with the porous structure of $\mathbf{1}$. Indeed, the adsorption heat values in the -30 to $-25 \mathrm{~kJ} \mathrm{~mol}^{-1}$ range (Fig. 3 inset in top) are indicative of a moderate interaction of the guest $\mathrm{CO}_{2}$ molecules with the inner voids of the MOP cages since no strong interacting sites are available and consequently the interaction is probably driven by the size of both intra and intercage micropores. In order to prove the adsorption selectivity of this system, we proceeded to estimate the $\mathrm{N}_{2} / \mathrm{CO}_{2}$ selectivity by measuring single component isotherms of both gases at $273 \mathrm{~K}$ (Fig. 3 down) which shows that selectivity $\alpha_{\mathrm{CO}_{2} / \mathrm{N}_{2}}$ values vary from 60 in the low pressure range to 25 at 1 bar.

In order to prove that the adsorption selectivity of $\mathbf{1}$ towards $\mathrm{CO}_{2}$ is maintained towards gas mixtures we have prepared a chromatographic column of this material $(0.35 \mathrm{~g})$ packed in a $15 \mathrm{~cm}$ long glass column with a $5 \mathrm{~mm}$ inner diameter and tested the separation process towards a simulated flue gas $\left(86 \%\right.$ of $\mathrm{N}_{2}$ and $14 \% \mathrm{CO}_{2}$ ). For this purpose, we proceeded to activate the packed chromatographic column under an He flow $\left(10 \mathrm{~mL} \mathrm{~min}^{-1}\right)$ at $403 \mathrm{~K}$ and after cooling down to $273 \mathrm{~K}$ we flowed a gas mixture containing $1.4 \mathrm{~mL} \mathrm{~min}{ }^{-1}$ of $\mathrm{CO}_{2}$ and $8.6 \mathrm{~mL} \mathrm{~min}^{-1}$ of $\mathrm{N}_{2}$. The results show (Fig. 4) that $\mathrm{CO}_{2}$ is selectively retained for $160 \mathrm{~s}$ which corresponds to the adsorption capacity of $0.5 \mathrm{mmol}$ of $\mathrm{CO}_{2} \mathrm{~g}^{-1}$ while $\mathrm{N}_{2}$ does not interact with the adsorbent.

In order to further prove the adsorption selective properties of this system we have also essayed the possible suitability of this material for the shape selective separation of benzene (b.p. $80.1{ }^{\circ} \mathrm{C}$ ) and cyclohexane (b.p. $80.7^{\circ} \mathrm{C}$ ) since separation by distillation is not suitable since the b.p. of both compounds differ in less than $1 \mathrm{~K}^{31}$ With this aim we have carried out variable-temperature pulse gas chromatography experiments in the 383-423 $\mathrm{K}$ temperature range with a complex gas mixture (methane, cyclohexene and benzene) in order to find out the possible resolution of this gas mixture by $\mathbf{1}$ (Fig. 5). The results show that $\mathbf{1}$ gives rise to negligible interactions with methane in the studied temperature range which is useful as a reference.

Noteworthily, while the benzene interaction seems to be strong as manifested by long retention times, broad peaks and high adsorption heat value $\left(-28.3 \mathrm{~kJ} \mathrm{~mol}^{-1}\right)$, the interaction with cyclohexene appears to be much weaker as manifested by lower retention times, sharper chromatographic peaks and low adsorption heat value $\left(-2.0 \mathrm{~kJ} \mathrm{~mol}^{-1}\right)$. Indeed, $\alpha_{\text {benzene/cyclohexane }}$ selectivity values of 10 are found which should be attributed to the smaller
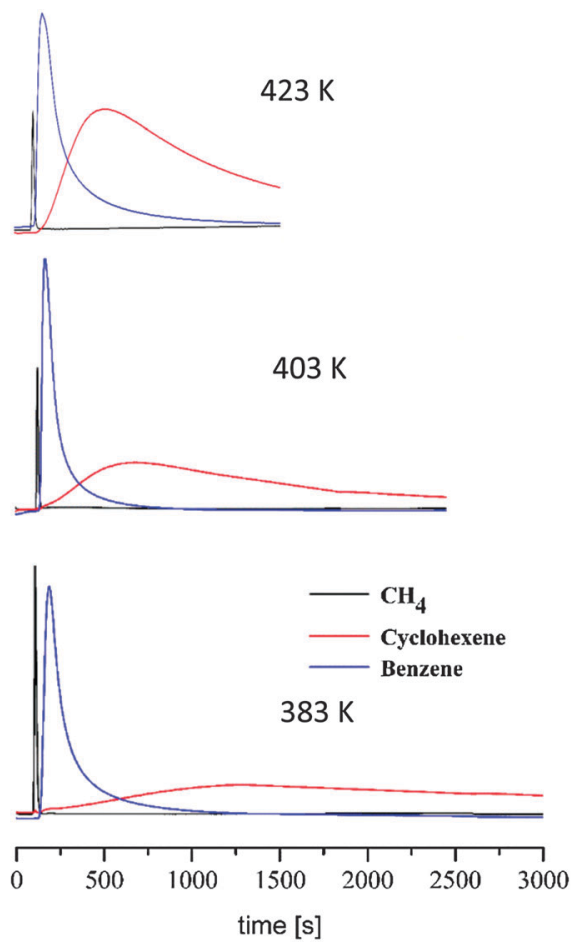

Fig. 5 Variable-temperature pulse gas chromatography experiments of an equimolecular $\mathrm{CH}_{4} /$ benzene/cyclohexene gas mixture passed through a chromatographic column packed with vanadium nanocages using a $\mathrm{He}$ flow of $10 \mathrm{~mL} \mathrm{~min}{ }^{-1}$.

size of benzene compared to cyclohexane which may facilitate the diffusion of benzene inside the MOP cavities justifying its higher retention while cyclohexane molecules are probably interacting with the external surface of the MOP microcrystalline powder.

In summary, a new vanadium MOP has been synthesized and fully characterized. It should be noted that in spite of the discrete nature of $\mathbf{1} \mathrm{MOP}$, the crystallographic study as well as the static and dynamic adsorption experiments reveal the accessibility of both the intra and intercage space to gas and VOC molecules giving rise to selective adsorption processes which are useful for carbon capture applications as well as shape separation of challenging benzene/ cyclohexane mixtures.

The authors thank Dr A. Lewińska of Wrocław University (EPR interpretation). We also thank Dr A. Rodriguez-Dieguez and Dr L. M. Rodriguez-Albelo of University of Granada for single crystal measurement and Connolly surface calculation. JARN is grateful to the Spanish Ministry of Economy and Competitiveness (CTQ2014-53486-R) for generous funding.

\section{Notes and references}

$\ddagger$ Crystal data for 1: $\mathrm{C}_{84} \mathrm{H}_{68} \mathrm{~N}_{24} \mathrm{O}_{40} \mathrm{~V}_{12}, M=2664.87 \mathrm{~g} \mathrm{~mol}^{-1}$, cubic, space group $I \overline{4} 3 m, a=b=c=20.084(5) \AA, V=8101(3) \AA^{3}, Z=2, \rho_{\text {calc }}=1.084 \mathrm{mg} \mathrm{m}^{-3}$, $T=100 \mathrm{~K}, \lambda_{\mathrm{MoK} \alpha}=0.71073 \AA, R\left(F, F^{2}>2 \sigma\right)=0.0683, R_{\mathrm{w}}\left(F^{2}\right.$, all data $)=0.1648$ for 497 unique reflections, goodness-of-fit $=1.250$. CCDC 1412183 .

1 H. Vardhana and F. Verpoort, Adv. Synth. Catal., 2015, 357, 1351.

2 F. Carmona, O. Palacios, N. Gálvez, R. Cuesta, S. Atrian, M. Capdevila and J. M. Domínguez-Vera, Coord. Chem. Rev., 2013, 257, 2752.

3 V. Guillerm, D. Kim, J. F. Eubank, R. Luebke, X. Liu, K. Adil, M. S. Lah and M. Eddaoudi, Chem. Soc. Rev., 2014, 43, 6141. 
4 Y. Han, J.-R. Li, Y. Xie and G. Guo, Chem. Soc. Rev., 2014, 43, 5952. 5 L.-B. Sun, J.-R. Li, W. Lu, Z.-Y. Gu, Z. Luo and H.-C. Zhou, J. Am. Chem. Soc., 2012, 134, 15923.

6 H. Vardhana and F. Verpoort, Adv. Synth. Catal., 2015, 357, 1351.

7 I. Swart, A. Fielicke, B. Redlich, G. Meijer, B. M. Weckhuysen and F. M. F. de Groot, J. Am. Chem. Soc., 2007, 129, 2516.

8 C. Ratsch, J. Chem. Phys., 2005, 122, 124302.

9 I. S. Tidmarsh, Inorg. Chem., 2007, 46, 9743.

10 A. Butler and C. J. Carrano, Coord. Chem. Rev., 1991, 109, 61.

11 Z. Janas, D. Wiśniewska, L. B. Jerzykiewicz, P. Sobota, K. Drabent and K. Szczegot, Dalton Trans., 2007, 2065.

12 Z. Janas and P. Sobota, Coord. Chem. Rev., 2005, 249, 2144.

13 C. Lorber, F. Wolff, R. Choukroun and L. Vendier, Eur. J. Inorg. Chem., 2005, 2850.

14 F. Wolff, C. Lorber, R. Choukroun and B. Donnadieu, Inorg. Chem., 2003, 42, 7839.

15 E. Y. Tshuva, N. Gendeziuk and M. Kol, Tetrahedron Lett., 2001, 42, 6405.

16 M. Sutradhar, G. Mukherjee, M. G. B. Drew and S. Ghosh, Inorg. Chem., 2006, 45, 5150.

17 D. Rehder, Bioinorganic Vanadium Chemistry, John Wiley \& Sons, Ltd., New York, 2008.

18 V. Chandrasekhar, A. Dey, T. Senapatia and E. C. Sanudo, Dalton Trans., 2012, 41, 799.

19 K. Barthelet, J. Marrot, D. Riou and G. Ferey, Angew. Chem., Int. Ed. Engl., 2002, 41, 281.

20 K. Barthelet, D. Riou, M. Nogues and G. Ferey, Inorg. Chem., 2003, 42, 1739 .
21 I. J. Kang, N. A. Khan, E. Haque and S. H. Jhung, Chemistry, 2011, 17, 6437.

22 W. Kaveevivitchai, X. Wang, L. Liu and A. J. Jacobson, Inorg. Chem., 2015, 54, 1822.

23 Y. Y. Liu, S. Couck, M. Vandichel, M. Grzywa, K. Leus, S. Biswas, D. Volkmer, J. Gascon, F. Kapteijn, J. F. M. Denayer, M. Waroquier, V. Van Speybroeck and P. Van Der Voort, Inorg. Chem., 2013, 52, 113.

24 A. Phan, A. U. Czaja, F. Gandara, C. B. Knobler and O. M. Yaghi, Inorg. Chem., 2011, 50, 7388.

25 C. Montoro, F. Linares, E. Quartapelle Procopio, I. Senkovska, S. Kaskel, S. Galli, N. Masciocchi, E. Barea and J. A. R. Navarro, J. Am. Chem. Soc., 2011, 133, 11888.

26 N. Masciocchi, S. Galli, A. Sironi, E. Cariati, M. A. Galindo, E. Barea, M. A. Romero, J. M. Salas, J. A. R. Navarro and F. Santoyo-González, Inorg. Chem., 2006, 45, 7612.

27 N. Masciocchi, S. Galli, G. Tagliabue, A. Sironi, O. Castillo, A. Luque, G. Beobide, W. Wang, M. A. Romero, E. Barea and J. A. R. Navarro, Inorg. Chem., 2009, 48, 3087.

28 E. Barea, C. Montoro and J. A. R. Navarro, Chem. Soc. Rev., 2014, 43, 5419.

29 S. Galli, N. Masciocchi, V. Colombo, A. Maspero, G. Palmisano, F. J. López-Garzón, M. Domingo-García, I. Fernández-Morales, E. Barea and J. A. R. Navarro, Chem. Mater., 2010, 22, 1664.

30 V. Colombo, C. Montoro, A. Maspero, N. Masciocchi, S. Galli, E. Barea and J. A. R. Navarro, J. Am. Chem. Soc., 2012, 134, 12830.

31 E. Quartapelle-Procopio, F. Linares, C. Montoro, V. Colombo, A. Maspero, E. Barea and J. A. R. Navarro, Angew. Chem., Int. Ed., 2010, 49, 7308. 